\title{
Self-reported quality of life of 8-12-year-old children with cerebral palsy: a cross-sectional European study
}

\author{
Heather O Dickinson, Kathryn N Parkinson, Ulrike Ravens-Sieberer, Giorgio Schirripa,* Ute Thyen, Catherine Arnaud, Eva Beckung, \\ Jérôme Fauconnier, Vicki McManus, Susan I Michelsen, Jackie Parkes, Allan F Colver
}

\begin{abstract}
Summary
Background Little is known about the quality of life (QoL) of disabled children. We describe self-reported QoL of children with cerebral palsy, factors that influence it, and how it compares with QoL of the general population.

Methods 1174 children aged 8-12 years were randomly selected from eight population-based registers of children with cerebral palsy in six European countries and $743(63 \%)$ agreed to participate; one further region recruited 75 children from multiple sources. Researchers visited these 818 children. 318 (39\%) with severe intellectual impairment could not self-report; 500 (61\%) reported their QoL using KIDSCREEN, an instrument with scores in ten domains, each with $\mathrm{SD}=10$. Multivariable regression was used to relate $\mathrm{Q}$ LL to impairments, pain, and sociodemographic characteristics. Comparisons were made with QoL data from the general population.
\end{abstract}

Findings Impairments were not significantly associated with six KIDSCREEN domains. Comparison of least and most able groups showed that severely limited self-mobility was significantly associated with reduced mean score for physical wellbeing $(7 \cdot 6,95 \%$ CI $2 \cdot 7-12 \cdot 4)$; intellectual impairment with reduced mean for moods and emotions $(3 \cdot 7,1 \cdot 5-5 \cdot 9)$ and autonomy $(3 \cdot 3,0 \cdot 9-5 \cdot 7)$; and speech difficulties with reduced mean for relationships with parents $(4 \cdot 5,1 \cdot 9-7 \cdot 1)$. Pain was common and associated with lower QoL on all domains. Impairments and pain explained up to $3 \%$ and 7\%, respectively, of variation in QoL. Children with cerebral palsy had similar QoL to children in the general population in all domains except schooling, in which evidence was equivocal, and physical wellbeing, in which comparison was not possible.

Interpretation Parents can be reassured that most children aged 8-12 years with cerebral palsy will have similar QoL to other children. This finding should guide social and educational policy to ensure that disabled children participate fully in society. Because of its association with QoL, children's pain should be carefully assessed.

\section{Introduction}

The UN Convention on the Rights of the Child, ${ }^{1}$ to which all European Union countries are signatories, states that children's views must be taken into account in all matters concerning them (article 12) and that disabled children are entitled to a "full and decent life" (article 23). Article 7 of the 2006 UN Convention on the Rights of Persons with Disabilities ${ }^{2}$ emphasises the right of disabled children to express their views.

Good quality of life (QoL) is a key outcome for the individual child and is what society wants for all children. QoL is defined by WHO as "an individual's perception of their position in life in the context of the culture and value systems in which they live, and in relation to their goals, expectations, standards and concerns". ${ }^{3}$ QoL is therefore subjective and so must be reported by the individual concerned whenever possible. This is a challenge when assessing children's QoL because they have typically been regarded as unreliable respondents. Evidence is accumulating that children can self-report QoL reliably if their emotional development, cognitive ability, and reading level are taken into account. ${ }^{5}$

Little is known about QoL of disabled children and previous studies usually included few children, ${ }^{6-8}$ did not use population-based samples, ${ }^{9-14}$ or relied on parental reports. ${ }^{9,12,14-17}$ A further difficulty in some studies that purport to capture QoL is that the instruments used focus on function and activities, ${ }^{18,19}$ therapeutic consequences, ${ }^{12}$ or effect on parents. ${ }^{9}$ Such studies inevitably rate disabled children lower than the general population, but it is misleading to call their outcome measures QoL because children's satisfaction with their lives might not correspond to their ability to undertake certain tasks or $\operatorname{activities}^{20}$ or to the consequences for their family.

Children with cerebral palsy have a range of impairments that are typically present in many disabled children. The objective of this report is to describe the QoL of children with cerebral palsy as reported by the children themselves, to identify factors that affect this QoL, and to compare it with the QoL of children in the general population.

The phrase "disabled child" rather than "child with disability" will be used in this paper, although we recognise that there are arguments for and against each phrase..$^{21}$ In particular, those in agreement with the social model of disability ${ }^{22}$ will agree with the phrase "child with impairment" but prefer "disabled child" because the child is disabled by society or the environment. The phrase "child with disability", although laudable for being child centred, nevertheless implies that the disability is something residing in or intrinsic to the child.
Lancet 2007; 369: 2171-78

See Comment page 2137

Institute of Health and Society (H O Dickinson PhD) and School of Clinical Medical Sciences (KN Parkinson PhD), Newcastle University, Newcastle upon Tyne, UK; Forschungsgruppe Psychosoziale Gesundheit, Robert Koch Institut, Berlin, Germany

(U Ravens-Sieberer PhD); Azienda Sanitaria Locale Viterbo, Viale Trento, Viterbo, Italy (G Schirripa MD); Klinik für Kinder- und Jugendmedizin Universitätsklinikum Schleswig-Holstein, Lübeck, Germany (UThyen MD); Institut National de la Santé et de la Recherche Médicale, Université Paul Sabatier, Faculté de Médecine, Toulouse, France (CArnaud MD); Göteborg University, The Queen Silvia Children's Hospital, Göteborg, Sweden (E Beckung PhD); Université Joseph Fournier, SIIM-Pole Exploitation, Grenoble, France (J Fauconnier MD); Enable Ireland, Lavanagh Centre, Ballintemple, Cork, Ireland (V McManus BA); National Institute of Public Health, Copenhagen, Denmark (SI Michelsen PhD); School of Nursing and Midwifery, Queen's University Belfast, Belfast, UK (J Parkes PhD); Sir James Spence Institute, Newcastle University, Royal Victoria Infirmary, Newcastle upon Tyne, UK (A F Colver MD) ${ }^{*}$ Dr Schirripa died in January, 2006 Correspondence to: Prof Allan F Colver, Sir James Spence Institute, Newcastle University, Royal Victoria Infirmary, Queen Victoria Road, Newcastle upon Tyne NE1 4LP, UK allan.colver@ncl.ac.uk 


\begin{tabular}{|c|c|c|}
\hline & $\begin{array}{l}\text { Measured perceptions of these aspects } \\
\text { of life }\end{array}$ & $\begin{array}{l}\text { Groups that reported poorer QoL } \\
\text { compared with other children }\end{array}$ \\
\hline $\begin{array}{l}\text { Physical } \\
\text { wellbeing (5) }\end{array}$ & Physical activity, energy, and fitness & $\begin{array}{l}\text { Girls, older children, and children whose } \\
\text { parents had a lower employment status }\end{array}$ \\
\hline $\begin{array}{l}\text { Psychological } \\
\text { wellbeing (6) }\end{array}$ & Positive emotions and satisfaction with life & $\begin{array}{l}\text { Older children, children living with one } \\
\text { parent, and children whose parents had } \\
\text { higher educational qualifications }\end{array}$ \\
\hline $\begin{array}{l}\text { Moods and } \\
\text { emotions (7) }\end{array}$ & Negative moods, boredom, and stress & $\begin{array}{l}\text { Girls and children whose parents had a } \\
\text { lower employment status }\end{array}$ \\
\hline $\begin{array}{l}\text { Self-perception } \\
\text { (5) }\end{array}$ & Self, bodily appearance, and body image & Girls and older children \\
\hline Autonomy (5) & $\begin{array}{l}\text { Freedom of choice and self-determination } \\
\text { in leisure time }\end{array}$ & $\begin{array}{l}\text { Children whose parents had higher } \\
\text { educational qualifications }\end{array}$ \\
\hline $\begin{array}{l}\text { Relationships } \\
\text { with parents (6) }\end{array}$ & $\begin{array}{l}\text { Interactions and relationships with parents } \\
\text { and the socioemotional atmosphere at home }\end{array}$ & $\begin{array}{l}\text { Older children and children whose parents } \\
\text { had higher educational qualifications }\end{array}$ \\
\hline $\begin{array}{l}\text { Social support } \\
\text { and peers (6) }\end{array}$ & $\begin{array}{l}\text { Social support available from friends } \\
\text { and peers }\end{array}$ & Boys \\
\hline $\begin{array}{l}\text { School } \\
\text { environment (6) }\end{array}$ & $\begin{array}{l}\text { Learning and feelings about school and } \\
\text { teachers }\end{array}$ & $\begin{array}{l}\text { Boys, older children, and children living } \\
\text { with one parent }\end{array}$ \\
\hline $\begin{array}{l}\text { Financial } \\
\text { resources (3) }\end{array}$ & $\begin{array}{l}\text { Adequacy of pocket money relative to } \\
\text { peers }\end{array}$ & $\begin{array}{l}\text { Younger children and children living with } \\
\text { one parent }\end{array}$ \\
\hline $\begin{array}{l}\text { Social } \\
\text { acceptance (3) }\end{array}$ & $\begin{array}{l}\text { Social acceptance or rejection by peers, } \\
\text { including bullying }\end{array}$ & $\begin{array}{l}\text { Children living with one parent and } \\
\text { children whose parents had lower } \\
\text { educational qualifications }\end{array}$ \\
\hline
\end{tabular}

Number of questions contributing to each domain is shown in parentheses.

Table 1: Description of each KIDSCREEN domain and the associations of QoL in each domain with sociodemographic characteristics for children in the general population

For more on KIDSCREEN see http://kidscreen. diehauptstadt.de/

\section{Methods \\ Participants and procedures}

The research is part of the wider Study of Participation of Children with Cerebral Palsy Living in Europe (SPARCLE), which examines how the QoL and participation of children with cerebral palsy relate to their environment, within the conceptual framework of the social model of disability. ${ }^{22}$ Only aspects relevant to this report are summarised below because the SPARCLE protocol, sampling strategy, participation rates, and potential bias have been reported in detail elsewhere. ${ }^{23,24}$

Children were eligible for the study if born between July 31, 1991, and April 1, 1997, and on registers of children with cerebral palsy that cover eight regions of six European countries (southeast France, southwest France, southwest Ireland, west Sweden, north England, Northern Ireland, east Denmark, and central Italy). There were 1884 such children. In regions with more than 200 registered children, we sampled so that the number who agreed to participate would be 100-120, and we sought similar numbers of children at each level of severity by grouping children by walking ability and selecting random samples from within strata. In other regions, we approached all eligible children. 1174 eligible families were approached and 743 (63\%) agreed to participate. ${ }^{24}$ A further region in northwest Germany recruited 75 children from multiple sources; the age, sex, and levels of impairment of these children were similar to those of children recorded on the population-based registers. ${ }^{24}$ Thus, the sample consisted of 818 children.
These children were visited at home in 2004-05 by researchers who administered questionnaires to parents and children, if possible when the children were $8-12$ years old. To suit family circumstances, 20 children were interviewed when just under 8 or just over 12. Parents were asked if their child would be able to understand a questionnaire, and if this was unclear their child's understanding was assessed by a test that required the child to order cubes of different sizes. ${ }^{25} 500$ (61\%) children were capable of reporting their own QoL and experience of pain. Of the 318 who could not self-report, 296 (93\%) had an IQ below 70 .

Self-reported QoL in the previous week was assessed with KIDSCREEN ${ }^{26}$ a modern instrument with excellent psychometric properties, which uses questions derived from focus-group work with children across Europe to assess the QoL of children and young people..$^{26-29}$

The ten domains of KIDSCREEN are summarised in table 1. Because translations in Danish and Italian were not available from the instrument's developers, these were undertaken according to international guidelines. ${ }^{30}$ Items are scored on a five-point scale and, within each domain, item scores are summed and transformed to Rasch person parameters by an algorithm that gives children in the reference population a mean score of 50 with an SD of $10 .^{29}$ The validity of this approach was confirmed for the children with cerebral palsy because all domains fulfilled the assumptions of a Rasch model and displayed no sizeable differential item functioning across disabled and non-disabled children (Erhart M, Robert Koch Institute, personal communication; full details are available on request from the corresponding author). Scores were available for more than $97 \%$ of children on all domains except perception of financial resources (89\%). The proportions of children scoring maximum and minimum values were similar to those reported for children in the general population. ${ }^{26}$ All domains had acceptable Cronbach $\alpha$ values ${ }^{31}$ of 0.7 or higher, except self-perception at $0 \cdot 59$.

Frequency and severity of pain were assessed with the two questions about pain from the Child Health Questionnaire, ${ }^{32}$ with the time period changed from 4 weeks to 1 week for consistency with KIDSCREEN. In the analysis, children who reported pain in response to either question were compared with those who did not.

Parents provided information about their employment, educational qualifications (table 2), and area of domicile (table 3), and about their child's gross motor function, ${ }^{3{ }^{3}}$ fine motor function, ${ }^{34}$ seizures, feeding, communication, intellect, school type, and siblings (table 3). Cerebral palsy type was available from the registers.

Comparative data for children in the general population were available from the developers of KIDSCREEN for children aged 8-12 years in five countries in the SPARCLE study:26 France, Germany, Ireland, Sweden, and the UK. The children's sex and age had been recorded in all five countries; family structure, parental employment, and 
educational qualifications had been recorded in all except Sweden and Ireland.

All parents gave written consent, and all children with sufficient cognitive capacity gave written consent or communicated consent if unable to write. Ethics approval was obtained from the ethics committee in each country.

\section{Statistical analysis}

Stata statistical software (version 9.2) was used for statistical analysis.

Regression models were used to relate each domain of children's QoL to sociodemographic characteristics, pain, and impairments. All models were adjusted for region (children with cerebral palsy) or country (general population). Linear regression was used for all KIDSCREEN domains except for social acceptance; because scores on this domain had a skewed distribution, with $48 \%$ of children achieving the maximum, logistic regression was used to compare children in the lowest quartile with the others. Initial models analysed each covariate in turn and excluded children with missing values on any of these covariates; the final multivariable models excluded only children with missing values on the included covariates. All factors were treated as categorical variables.

We first assessed how QoL of children in the general population varied with sociodemographic characteristics. For each KIDSCREEN domain, we used regression to relate QoL to each sociodemographic characteristic (sex and age of the child, family structure, and employment and educational qualifications of the parents) in turn, while adjusting for country. Because family and parental characteristics were not recorded in two countries, we included these characteristics in the models by treating them as interactions with country. All factors identified as significant $(\mathrm{p}<0 \cdot 3)^{35}$ were then included in a multivariable model and the least significant factors $(p>0.05)$ were then successively removed. Interactions between main effects of age, sex, and country were included if they were statistically significant $(p<0 \cdot 05)$. $p$ values were derived from the likelihood ratio test statistic.

We next assessed how QoL of children with cerebral palsy varied with impairments and pain. Children were assigned sampling weights to allow for the sampling strategy; therefore, robust SE values and Wald p values were used. $^{36}$ For each KIDSCREEN domain, we used regression to relate QoL to pain, impairments, and the additional sociodemographic characteristics available only for disabled children (type of school, siblings, and area of domicile), considering each factor separately. We adjusted these regressions for the sex and age of the child, family structure, and parental employment and educational qualifications using the relations estimated from the general population (external adjustment using offsets), and we made additional internal adjustment for region. Final multivariable models were developed with the aforementioned backwards stepwise procedure, but to lessen the probability of chance findings due to multiple

\begin{tabular}{|c|c|c|c|}
\hline & $\begin{array}{l}\text { Number from } \\
\text { general population } \\
(\mathrm{n}=3219)\end{array}$ & $\begin{array}{l}\text { Number with cerebral palsy } \\
\text { in countries with general } \\
\text { population data }(n=379)\end{array}$ & $\begin{array}{l}\text { Total number } \\
\text { with cerebral } \\
\text { palsy }(n=500)\end{array}$ \\
\hline \multicolumn{4}{|l|}{ Country and region } \\
\hline France: & $512(16 \%)$ & $85(22 \%)$ & $85(17 \%)$ \\
\hline Southeast &.. & 38 & 38 \\
\hline Southwest & .. & 47 & 47 \\
\hline Germany: northwest & $798(25 \%)$ & $45(12 \%)$ & $45(9 \%)$ \\
\hline Ireland: southwest & $359(11 \%)$ & $67(18 \%)$ & $67(13 \%)$ \\
\hline Sweden: west & $406(13 \%)$ & $46(12 \%)$ & $46(9 \%)$ \\
\hline UK: & $1144(36 \%)$ & $136(36 \%)$ & $136(27 \%)$ \\
\hline North England &. & 78 & 78 \\
\hline Northern Ireland & .. & 58 & 58 \\
\hline Denmark: east & NA & NA & $81(16 \%)$ \\
\hline Italy: central & NA & NA & $40(8 \%)$ \\
\hline \multicolumn{4}{|l|}{ Sex } \\
\hline Boys & $1611(50 \%)$ & $219(58 \%)$ & $286(57 \%)$ \\
\hline Girls & $1602(50 \%)$ & $160(42 \%)$ & $214(43 \%)$ \\
\hline Information not available & $6(0 \%)$ & $0(0 \%)$ & $0(0 \%)$ \\
\hline \multicolumn{4}{|l|}{ Age (years) } \\
\hline 7 & $0(0 \%)$ & $3(1 \%)$ & $7(1 \%)$ \\
\hline 8 & $372(12 \%)$ & $73(19 \%)$ & $98(20 \%)$ \\
\hline 9 & $611(19 \%)$ & $86(23 \%)$ & $105(21 \%)$ \\
\hline 10 & $717(22 \%)$ & $76(20 \%)$ & $93(19 \%)$ \\
\hline 11 & $608(19 \%)$ & $81(21 \%)$ & $105(21 \%)$ \\
\hline 12 & $911(28 \%)$ & $56(15 \%)$ & $79(16 \%)$ \\
\hline 13 & $0(0 \%)$ & $4(1 \%)$ & $13(3 \%)$ \\
\hline \multicolumn{4}{|l|}{ Family structure* } \\
\hline Married or living with partner & $1965(80 \%)$ & $306(81 \%)$ & $408(82 \%)$ \\
\hline Single & $154(6 \%)$ & $73(19 \%)$ & $92(18 \%)$ \\
\hline Information not available & $335(14 \%)$ & $0(0 \%)$ & $0(0 \%)$ \\
\hline \multicolumn{4}{|l|}{ Parental employment ${ }^{*}$} \\
\hline $\begin{array}{l}\text { At least one parent works full time } \\
\text { professionally (or equivalent) }\end{array}$ & $959(39 \%)$ & $95(25 \%)$ & $132(26 \%)$ \\
\hline Intermediate & $965(39 \%)$ & $200(53 \%)$ & $260(52 \%)$ \\
\hline $\begin{array}{l}\text { One parent works part time } \\
\text { or neither parent works }\end{array}$ & $497(20 \%)$ & $84(22 \%)$ & $106(21 \%)$ \\
\hline Information not available & $33(1 \%)$ & $0(0 \%)$ & $2(1 \%)$ \\
\hline \multicolumn{4}{|l|}{ Parental educational qualifications* } \\
\hline Above university entrance & $741(30 \%)$ & $73(19 \%)$ & $126(25 \%)$ \\
\hline Intermediate & $1025(42 \%)$ & $204(54 \%)$ & $260(52 \%)$ \\
\hline Lowest formal qualification or none & $278(11 \%)$ & $99(26 \%)$ & $111(22 \%)$ \\
\hline Information not available & $410(17 \%)$ & $3(1 \%)$ & $3(1 \%)$ \\
\hline \multicolumn{4}{|c|}{$\begin{array}{l}\mathrm{NA}=\text { general population data not available for Denmark and Italy. } \cdot \cdots=\text { not applicable because general population data } \\
\text { were from a national sample. }{ }^{*} \text { Excluding general population in Sweden and Ireland. }\end{array}$} \\
\hline
\end{tabular}

hypothesis testing, the $\mathrm{p}$ value for removal of factors from the multivariable model was set at $p>0 \cdot 01$. For factors with several ordinal categories, $p$ values for trend were assessed. Models were checked for interactions, influence and sensitivity analyses were undertaken, and plots of residuals were examined. To investigate whether pain mediated a relation between impairments and QoL, we used logistic regression to relate pain to impairments, adjusting for region. 


\begin{tabular}{|c|c|}
\hline & Number (\%) \\
\hline \multicolumn{2}{|l|}{ Impairment } \\
\hline \multicolumn{2}{|l|}{ Gross motor function } \\
\hline I Walks and climbs stairs, without limitation & $218(44 \%)$ \\
\hline II Walks with limitations & $118(24 \%)$ \\
\hline III Walks with assistive devices & $93(19 \%)$ \\
\hline IV Unable to walk, limited self-mobility & $49(10 \%)$ \\
\hline V Unable to walk, severely limited self-mobility & $22(4 \%)$ \\
\hline \multicolumn{2}{|l|}{ Bimanual fine motor function } \\
\hline I Few restrictions & $241(48 \%)$ \\
\hline$\|\&\| \|$ Moderate restrictions & $219(44 \%)$ \\
\hline IV\&V Severe restrictions & $40(8 \%)$ \\
\hline \multicolumn{2}{|l|}{ Seizures } \\
\hline No seizures (either with or without medication) & $456(91 \%)$ \\
\hline Seizures & $44(9 \%)$ \\
\hline \multicolumn{2}{|l|}{ Feeding } \\
\hline No problems & $446(89 \%)$ \\
\hline Feeds orally with difficulty, or by tube & $54(11 \%)$ \\
\hline \multicolumn{2}{|l|}{ Communication } \\
\hline Normal & $409(82 \%)$ \\
\hline Difficulty but uses speech & $66(13 \%)$ \\
\hline Uses non-speech for formal communication & $25(5 \%)$ \\
\hline No formal communication & $0(0 \%)$ \\
\hline \multicolumn{2}{|l|}{ Intellectual impairment } \\
\hline None or mild (IQ >70) & $363(73 \%)$ \\
\hline Moderate or severe (IQ $\leq 70)$ & $134(27 \%)$ \\
\hline Information not available & $3(1 \%)$ \\
\hline \multicolumn{2}{|l|}{ Cerebral palsy subtype } \\
\hline Unilateral spastic & $220(44 \%)$ \\
\hline Bilateral spastic & $235(47 \%)$ \\
\hline Dyskinetic or ataxic & $44(9 \%)$ \\
\hline Information not available & $1(0 \%)$ \\
\hline \multicolumn{2}{|l|}{ Pain } \\
\hline Reported no pain during previous week & $217(43 \%)$ \\
\hline Reported pain during previous week & $272(54 \%)$ \\
\hline Information not available & $11(2 \%)$ \\
\hline \multicolumn{2}{|l|}{ Sociodemographic characteristics } \\
\hline \multicolumn{2}{|l|}{ Schooling } \\
\hline Mainstream school & $290(58 \%)$ \\
\hline Mainstream school and visits special unit & $65(13 \%)$ \\
\hline Special unit in mainstream school & $46(9 \%)$ \\
\hline Special school & $97(19 \%)$ \\
\hline Information not available & $2(0 \%)$ \\
\hline \multicolumn{2}{|l|}{ Siblings } \\
\hline None & $86(17 \%)$ \\
\hline One or more, none disabled & $347(69 \%)$ \\
\hline One or more, one or more disabled & $58(12 \%)$ \\
\hline Information not available & $9(2 \%)$ \\
\hline \multicolumn{2}{|l|}{ Area of domicile } \\
\hline City & $79(16 \%)$ \\
\hline Town or suburbs & $244(49 \%)$ \\
\hline Village or countryside & $175(35 \%)$ \\
\hline Information not available & $2(0 \%)$ \\
\hline
\end{tabular}

Finally, we compared QoL of children with cerebral palsy with that of children in the general population of the five countries in SPARCLE for which general population data were available. For each KIDSCREEN domain (except for physical wellbeing, which needed a minor amendment to one item to make it more suitable for children with cerebral palsy), multivariable regression was used to compare QoL in children with cerebral palsy with that in the general population, both unadjusted and adjusted for country and for sociodemographic characteristics that were significant in the general population.

\section{Role of the funding source}

The funding source and sponsor, the European Commission, had no role in study design, data collection, data analysis, data interpretation, or writing of the report. The corresponding author had full access to all the data in the study and had final responsibility for the decision to submit for publication.

\section{Results}

The general population sample consisted of 3219 children whose sociodemographic characteristics are shown in table 2 . The final multivariable models, adjusted for country, are summarised in the right-hand column of table 1. QoL on all domains varied with sociodemographic factors-in particular sex, age, parental employment status, parental educational qualifications, and whether the child lived with one or two parents. However, these models explained only $4-13 \%$ of the variation in QoL. There were no significant interactions between age, sex, and country.

500 (61\%) of the 818 children in the SPARCLE study self-reported their QoL. Tables 2 and 3 summarise the number of children with cerebral palsy who were recruited in each geographical area and the type and severity of impairments, experience of pain, and sociodemographic characteristics of these children. More than half reported pain in the previous week but logistic regression indicated that pain was not significantly associated with any impairments: for example, the odds ratio comparing reporting of pain by children who were unable to walk with that of children who walked "without limitation" (ie, gross motor function classifications IV and $\mathrm{V}$ vs I) was $1 \cdot 0$ (95\% CI 0.5-1.7).

We then examined how QoL on each KIDSCREEN domain varied with impairments, pain, type of school, siblings, and area of domicile, analysing each of these factors separately but adjusting for region and for the relations between QoL and sociodemographic characteristics that were significant in the general population (detailed results of regression models are available from the corresponding author on request). Impairments were not significantly associated with QoL on six domains: psychological wellbeing, self-perception, social support and peers, school environment, financial resources, and social acceptance (all $\mathrm{p}>0 \cdot 01)$. Children who reported pain in the previous week tended to report a lower QoL on 
all ten domains, although the association was statistically significant for only five.

The relation of QoL with impairments and pain differed little between the aforementioned models-which included each type of impairment separately-and the final multivariable models (table 4), indicating the absence of association between these factors. Specific impairments were associated with poorer QoL for only four domains: poorer walking ability was associated with poorer physical wellbeing; intellectual impairment was associated with poorer moods and emotions and with less autonomy; and speech difficulty was associated with poorer relationships with parents. Pain was significantly associated with poorer QoL for these four domains and also for the self-perception and school domains.

These associations were confirmed by sensitivity analysis with weights that allowed for non-response. Although poorer walking ability was significantly associated with better QoL on the school domain in the primary analysis, this trend was not significant in the sensitivity analysis and so was omitted from the final model. Further sensitivity analysis, with internal adjustment for all sociodemographic characteristics, yielded similar results. There were no significant interactions between the main effects in the final models. Exclusion of children with the largest residuals changed the estimates little. Plots of residuals showed no systematic pattern, but the variance of QoL was generally lower for extreme values, so significant findings should be interpreted cautiously.

In the final multivariable model, impairments, pain, and region together accounted for up to $17 \%$ of the variation in $\mathrm{QoL}$; in univariable models, they accounted for up to $3 \%, 7 \%$, and $8 \%$, respectively (table 5 ).

Finally, we compared the QoL of the 379 children with cerebral palsy in France, Germany, Ireland, Sweden, and the UK with that of children in the general population in these countries. The children with cerebral palsy were more likely than children in the general population to be boys and children under 12 years, to live with a single parent, and to have parents with lower employment status and lower educational qualifications (table 2). The QoL of the two groups is summarised in the figure.

Physical wellbeing was not formally analysed because the questions in this domain had required slight modification for children with cerebral palsy. Multivariable regression indicated that the QoL of the children with cerebral palsy was similar to that of children in the general population in all other domains except for the school environment, where children with cerebral palsy had significantly better QoL ( $\mathrm{p} \leq 0 \cdot 001)$, both unadjusted and after adjustment for country; further adjustment for all relevant sociodemographic characteristics gave similar results. However, in Northern Ireland, which had a high non-response rate $(51 \%)$, children with cerebral palsy had a higher QoL for all domains than did other children in the UK (both those with cerebral palsy in north England and those in the general population of the UK). Sensitivity

\begin{tabular}{|c|c|c|}
\hline & $b^{*}(95 \% \mathrm{Cl})$ & $\mathrm{p}$ \\
\hline \multicolumn{3}{|l|}{ Physical wellbeing $(n=481)$} \\
\hline \multicolumn{3}{|l|}{ Gross motor function } \\
\hline I Walks and climbs stairs, without limitation & 0.0 & NA \\
\hline II Walks with limitations & $-0.7(-3.5$ to $2 \cdot 2)$ & 0.65 \\
\hline III Walks with assistive devices & $-1 \cdot 8(-5 \cdot 1$ to $1 \cdot 5)$ & 0.28 \\
\hline IV Unable to walk, limited self-mobility & $-4 \cdot 0(-7.7$ to -0.4$)$ & 0.03 \\
\hline V Unable to walk, severely limited self-mobility & $-7 \cdot 6(-12 \cdot 4$ to $-2 \cdot 7)$ & 0.002 \\
\hline $\mathrm{p}$ for trend & & 0.005 \\
\hline \multicolumn{3}{|l|}{ Pain } \\
\hline Reported no pain during previous week & 0.0 & NA \\
\hline Reported pain during previous week & $-6 \cdot 4(-8 \cdot 9$ to $-4 \cdot 0)$ & $<0.0001$ \\
\hline Psychological wellbeing & \multicolumn{2}{|c|}{$\begin{array}{l}\text { Not significantly associated with any of the } \\
\text { factors considered }\end{array}$} \\
\hline \multicolumn{3}{|l|}{ Moods and emotions $(n=473)$} \\
\hline \multicolumn{3}{|l|}{ Intellectual impairment } \\
\hline None or mild (IQ>70) & 0.0 & NA \\
\hline Moderate or severe $(\mathrm{IQ} \leq 70)$ & $-3 \cdot 7(-5 \cdot 9$ to $-1 \cdot 5)$ & 0.001 \\
\hline \multicolumn{3}{|l|}{ Pain } \\
\hline Reported no pain during previous week & 0.0 & NA \\
\hline Reported pain during previous week & $-3 \cdot 5(-5 \cdot 4$ to $-1 \cdot 6)$ & 0.0003 \\
\hline \multicolumn{3}{|l|}{ Self-perception $(n=482)$} \\
\hline \multicolumn{3}{|l|}{ Pain } \\
\hline Reported no pain during previous week & 0.0 & NA \\
\hline Reported pain during previous week & $-3.0(-5 \cdot 2$ to -0.9$)$ & 0.005 \\
\hline \multicolumn{3}{|l|}{ Autonomy $(n=481)$} \\
\hline \multicolumn{3}{|l|}{ Intellectual impairment } \\
\hline None or mild (IQ>70) & 0.0 & NA \\
\hline Moderate or severe (IQ $\leq 70)$ & $-3 \cdot 3(-5 \cdot 7$ to -0.9$)$ & 0.006 \\
\hline \multicolumn{3}{|l|}{ Pain } \\
\hline Reported no pain during previous week & 0.0 & NA \\
\hline Reported pain during previous week & $-4 \cdot 7(-6 \cdot 8$ to $-2 \cdot 6)$ & $<0.0001$ \\
\hline \multicolumn{3}{|l|}{ Relationships with parents $(\mathrm{n}=480)$} \\
\hline \multicolumn{3}{|l|}{ Communication } \\
\hline Normal speech & 0.0 & NA \\
\hline Difficulty with speech or no speech & $-4 \cdot 5(-7 \cdot 1$ to $-1 \cdot 9)$ & 0.001 \\
\hline \multicolumn{3}{|l|}{ Pain } \\
\hline Reported no pain during previous week & 0.0 & NA \\
\hline Reported pain during previous week & $-3 \cdot 1(-5 \cdot 3$ to $-0 \cdot 8)$ & 0.007 \\
\hline Social support and peers & \multicolumn{2}{|c|}{$\begin{array}{l}\text { Not significantly associated with any of the } \\
\text { factors considered }\end{array}$} \\
\hline \multicolumn{3}{|l|}{ School environment $(n=485)$} \\
\hline \multicolumn{3}{|l|}{ Pain } \\
\hline Reported no pain during previous week & 0.0 & NA \\
\hline Reported pain during previous week & $-4 \cdot 8(-7 \cdot 2$ to $-2 \cdot 4)$ & $<0.0001$ \\
\hline Financial resources & \multicolumn{2}{|c|}{$\begin{array}{l}\text { Not significantly associated with any of the } \\
\text { factors considered }\end{array}$} \\
\hline Social acceptance & \multicolumn{2}{|c|}{$\begin{array}{l}\text { Not significantly associated with any of the } \\
\text { factors considered }\end{array}$} \\
\hline
\end{tabular}

Regression models are adjusted for region and for sociodemographic characteristics. $n=n u m b e r$ of children included in model. NA=not applicable. *b-coefficients indicate the difference in QoL between the relevant category and the reference category; b-coefficients $<0$ indicate a lower QoL in the corresponding category.

Table 4: Multivariable linear regression models relating KIDSCREEN domains to impairment and pain in children with cerebral palsy

analysis that excluded this group showed no significant difference between the QoL of disabled children and the 
general population in the school domain $(\mathrm{p}=0 \cdot 23)$ but autonomy was significantly lower $(\mathrm{p}=0 \cdot 004)$ in the children with cerebral palsy.

\section{Discussion}

For children with cerebral palsy, type and severity of impairments were not associated with QoL for six KIDSCREEN domains: psychological wellbeing, selfperception, social support, school environment, financial resources, and social acceptance. Specific impairments were associated with poorer QoL in the four other domains: children with poorer walking ability had poorer physical wellbeing; those with intellectual impairment had lower moods and emotions and less autonomy; and those with speech difficulty had poorer relationships with their parents. Despite these associations, impairments explained little of the variation in the QoL of children with cerebral palsy. Average differences in QoL between children with

\begin{tabular}{lllll|}
\hline & $\mathbf{r}^{\mathbf{2}}$ impairment $^{*}$ & $\mathbf{r}^{\mathbf{2}}$ pain $^{*}$ & $\mathbf{r}^{\mathbf{2}}$ region & $\mathbf{R}^{\mathbf{2}}$ total $\boldsymbol{~}$ \\
\hline Physical wellbeing & $2 \%$ & $7 \%$ & $8 \%$ & $17 \%$ \\
Moods and emotions & $3 \%$ & $4 \%$ & $3 \%$ & $9 \%$ \\
Self-perception & NA & $3 \%$ & $6 \%$ & $8 \%$ \\
Autonomy & $2 \%$ & $6 \%$ & $8 \%$ & $14 \%$ \\
Relationships with parents & $3 \%$ & $3 \%$ & $6 \%$ & $11 \%$ \\
School environment & NA & $6 \%$ & $8 \%$ & $11 \%$ \\
\hline
\end{tabular}

$N A=$ not applicable because QoL on this domain was not significantly associated with impairment. ${ }^{2}{ }^{2}$ is \% variance explained by impairment, pain, and region in seperate univariable models. $t R^{2}$ is \% variance explained jointly by impairment, pain, and region in multivariable models.

Table 5: Percentage of variation explained by univariable and multivariable linear regression models relating KIDSCREEN domains to impairment and pain in children with cerebral palsy

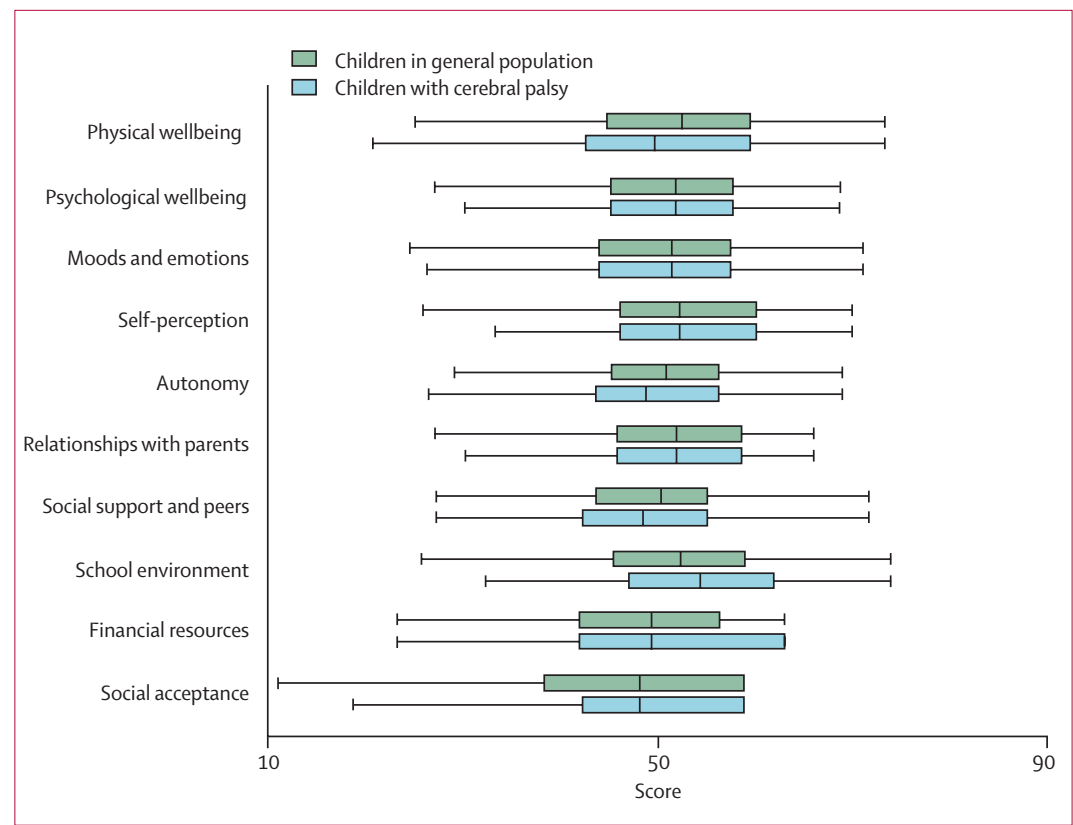

Figure: Box and whisker plots of KIDSCREEN quality of life scores by domain for children with cerebral palsy and children in the general population

The scales for each domain have mean $=50$ and SD=10 in the reference population. ${ }^{26}$ gross motor function levels I and V were less than $1 \mathrm{SD}$ of the QoL in the general population. ${ }^{26}$ Differences between children with and without intellectual and communication impairment were of similar magnitude to the combined effect of social factors such as parental education, parental employment, and family structure.

Pain was associated with poorer QoL for all domains but explained little of the variation in QoL. It was not significantly associated with impairments.

The QoL of children with cerebral palsy was, on average, similar to that of children of the same age in the general population in all domains except for the school environment, in which it was better. However, sensitivity analysis indicated that there might be little difference in the school domain, and that autonomy might be lower in the disabled children than in the general population.

This study has several strengths: participants were sampled from children with cerebral palsy in nine defined geographic areas, eight of which had population-based registers; QoL was captured with a new European questionnaire (KIDSCREEN) that has strong psychometric validity, was developed by eliciting the views of children, ${ }^{26,27}$ and is based on a sound theoretical framework that emphasised perception of psychosocial aspects of wellbeing rather than functioning or symptoms; QoL was reported by children themselves rather than by parents or other proxies; and all children who self-reported were included, irrespective of their impairments. However, some children with intellectual impairment cannot self-report and interpretation of their parent-reported QoL presents special problems ${ }^{37}$ which we are examining and will report separately.

Although $37 \%$ of families of children with cerebral palsy were non-responders, we have previously investigated the potential for non-response bias, ${ }^{24}$ and in the present report we allowed for different levels of non-response in different groups in a sensitivity analysis. Nevertheless, the QoL of non-responders might have been systematically different from that of responders, and so additional bias could be present. Such potential bias might explain the apparently better QoL at school of the children with cerebral palsy compared with the general population. Furthermore, these samples came from separate studies, ${ }^{26}$ and regional samples of disabled children were compared with national samples of the general population. Ideally, children with cerebral palsy would have been compared with concurrent samples from non-disabled children, but the additional cost of visiting even one control for each child with cerebral palsy would have been prohibitive. Use of the KIDSCREEN general population data, which were obtained only 2 years previously from a large sample in European countries covered by our study, was a reasonable compromise.

Previous studies of children with cerebral palsy provide conflicting evidence about the relation of QoL to motor impairment, and few examine other impairments. Varni and colleagues $^{11}$ used the PedsQL instrument on a convenience sample of 69 children aged 5-18 years; in this study, QoL was significantly poorer for the four domains of 
PedsQL-physical, emotional, social, and school function-in children with bilateral spastic cerebral palsy than in those with unilateral cerebral palsy, whereas we identified no significant associations between QoL and laterality. However, the social and school domains used by Varni and colleagues included questions about function and participation, whereas KIDSCREEN focuses entirely on subjective perceptions. Two studies ${ }^{9,14}$ used parental reports from the Child Health Questionnaire; this questionnaire captures aspects of function, physical health, and effect on family, ${ }^{32}$ but only two of its domains-psychological wellbeing and self-esteemoverlap with KIDSCREEN. In the first study, QoL was poorer in more impaired children; ${ }^{9}$ in the second, epilepsy was associated with poorer self-esteem, but neither intellectual nor motor impairment was associated with self-esteem or psychological wellbeing..$^{14}$ A population-based study of parental reports for children aged 5-13 years reported, as we did, no association between severity of motor impairment and emotional wellbeing. ${ }^{15}$ Studies in disabled children without cerebral palsy had contrasting findings: for example, in children with mobility impairment ${ }^{38}$ or spina bifida ${ }^{17}$ severity of impairment was not related to QoL, but in children with arthritis it was. ${ }^{39}$

Few studies have compared self-reported QoL of children aged 8-12 years who have cerebral palsy with that of the general population of the same age. In their study of children aged 5-18 years, Varni and colleagues ${ }^{11}$ reported that QoL was lower than in the general population but they did not report scores by age group. A recent systematic review $^{8}$ of self-concept in children with cerebral palsy covered six of the KIDSCREEN domains but included only six suitable studies, the largest of which assessed only 64 children; there was insufficient evidence to establish whether self-concept was lower in the disabled children than in those without cerebral palsy. Studies of children with spina bifida, ${ }^{40}$ rheumatoid arthritis, ${ }^{7}$ physical impairments, ${ }^{6,13,41}$ and behaviour and learning difficulties ${ }^{10}$ provide conflicting evidence about how the QoL of these children compares with that of the general population. It is difficult to compare these studies with each other or with our study because of the small numbers, ${ }^{6,70,40,41}$ non-representative samples, ${ }^{6,70,41}$ and different age ranges. ${ }^{6,7,10,13,40,41}$

The lack of association between pain and impairments in our study could be because we excluded children who could not self-report, reducing statistical power in the group of children with severe intellectual impairment who are more likely to have severe motor and other impairments. However, our finding is supported by a population study ${ }^{15}$ that elicited parents' reports of their children's pain.

Our finding that pain was associated with poorer QoL on all domains is confirmed by studies of children with cerebral palsy, ${ }^{15,16}$ mobility impairment, ${ }^{38}$ and arthritis. ${ }^{42,43}$ In our sample, $54 \%$ had experienced pain in the previous week, a higher prevalence than in the general population. ${ }^{446}$ However, we did not study the source of the pain, which could be similar to the general pains that all children experience. Furthermore, children with poor QoL might perceive pain differently or report emotional distress as pain.

We think our robust study design, with large numbers of children from several countries, sampling from population registers, and an instrument for self-reporting directed at the subjective, allows our conclusions to resolve apparent conflicts in previous results.

Whereas specific domains of QoL of children with cerebral palsy are associated with specific impairments, QoL on most aspects of life is not associated with impairments and is therefore likely to be determined largely by social and environmental factors, although these might differ between children with cerebral palsy and those with no disability.

Our cross-sectional design cannot attribute causality, but improvement in physical function might plausibly enhance physical wellbeing, and improvement in speech and communication might plausibly improve a child's perception of relationships with parents and home life. Every effort should be made to ask about and treat pain because it is common in children with cerebral palsy and is associated with reduced QoL across all domains. The effectiveness of such interventions should be assessed in randomised controlled trials.

Is it surprising that subjective QoL of children with cerebral palsy is similar to that of the general population? Possibly, from the perspective of a non-disabled adult imagining what it would be like to be disabled, ${ }^{47}$ but probably not from the perspective of a child whose sense of self from birth incorporates their impairment and who embraces growth, development, and living with the same excitement as most children. Many parents are upset when their child is diagnosed with cerebral palsy, but they can now be reassured that most children with cerebral palsy who can provide information when 8-12 years old experience similar QoL to that of other children of their age.

There is widespread acceptance of the need for disabled children to be integrated fully into society.,2 The change now needed concerns attitudes. Pity and sorrow should not be directed to disabled children because our findings indicate that they experience most of life as do non-disabled children. Therefore, maximum effort is needed to support social and educational policies that recognise the similarity between the lives of disabled children and those of other children, and that ensure their right as citizens, rather than as disabled children, to participate fully in society.

\section{Contributors}

AFC, GS, UT, CA, EB, JF, VM, SIM, and JP participated in the planning of the study. AFC coordinated the study and took overall responsibility for the delivery of the work. GS, UT, CA, EB, JF, VM, SIM, and JP had

responsibility for data collection. UR-S provided full information about the KIDSCREEN instrument, coordinated the collection of general population data, and assisted with its validation for the disabled children in this study. HOD did the statistical analysis. KNP was responsible for the day-to-day administration of the study and data collection in one centre. AFC, HOD, and KNP participated in writing the paper. All authors have seen and approved the final version. 
Conflict of interest statement

We declare that we have no conflict of interest.

\section{Acknowledgments}

We thank the families who participated in SPARCLE; the research associates of this study-Kerry Anderson, Barbara Caravale, Malin Carlsson, Eva Lise Eriksen, Delphine Fenieys, Bettina Gehring, Louise Gibson, Heidi Kiecksee, Ann Madden, and Ondine Pez-for their enthusiasm and dedication in contacting families and collecting high-quality data; and Michael Erhart for the analysis of differential item functioning. The study is funded by the European Union Research Framework 5 Programme, Grant number QLG5-CT-2002-00636.

\section{References}

1 United Nations. Convention on the rights of the child. New York: United Nations, 1989.

2 United Nations. Convention on the rights of persons with disabilities. Resolution 60/232. New York: United Nations, 2006.

3 WHO. The World Health Organization quality of life assessment (WHOQOL): position paper from the World Health Organization. Soc Sci Med 1995; 41: 1403-09.

4 Eiser C, Morse R. Quality-of-life measures in chronic diseases of childhood. Health Technol Assess 2001; 5: 1-157.

5 Riley A. Evidence that school-age children can self-report on their health. Ambul Pediatr 2004; 4: 371-76.

6 Arnold P, Chapman M. Self-esteem, aspirations and expectations of adolescents with physical disability. Dev Med Child Neurol 1992; 34: 97-102.

7 Kuczynski E, Silva CA, Cristofani LM, Kiss MH, Odone Filho V, Assumpcao FB Jr. Quality of life evaluation in children and adolescents with chronic and/or incapacitating diseases: a Brazilian study. Ann Pediatr (Paris) 2003; 58: 550-55.

8 Shields N, Murloch A, Loy Y, Dodd K, Taylor N. A systematic review of the self-concept of children with cerebral palsy compared with children without disability. Dev Med Child Neurol 2006; 48 : 151-57.

9 Vargus-Adams J. Health-related quality of life in childhood cerebral palsy. Arch Phys Med Rehabil 2005; 86: 940-45.

10 Watson SMR, Keith KD. Comparing the quality of life of school-age children with and without disabilities. Ment Retard 2002; 40: 304-12.

11 Varni JW, Burwinkle TM, Sherman SA, et al. Health-related quality of life of children and adolescents with cerebral palsy: hearing the voices of children. Dev Med Child Neurol 2005; 48: 592-97.

12 Liptak GS, O'Donnell M, Conaway M, et al. The health status of children with moderate to severe cerebral palsy. Dev Med Child Neurol 2001; 43: 364-70.

13 Grue L. Do adolescents with disabilities view themselves different from other young people? Dev Med Child Neurol 2003; 45 (October suppl): 8 (abstr)

14 Wake M, Salmon L, Reddihough D. Health status of Australian children with mild to severe cerebral palsy: cross-sectional survey using the Child Health Questionnaire. Dev Med Child Neurol 2003; 45: 194-99.

15 Kennes J, Rosenbaum P, Hanna SE, et al. Health status of school-aged children with cerebral palsy: information from a population-based sample. Dev Med Child Neurol 2002; 44: 240-57.

16 Houlihan CM, O'Donnell M, Conaway M, Stevenson RD. Bodily pain and health-related quality of life in children with cerebral palsy. Dev Med Child Neurol 2004; 46: 305-10.

17 Rendeli C, Ausili E, Tabacco F, et al. Assessment of health status in children with spina bifida. Spinal Cord 2005; 43: 230-35.

18 Pirpiris M, Gates PE, McCarty JJ, et al. Function and well-being in ambulatory children with cerebral palsy. J Pediatr Orthop 2006; 26 119-24.

19 McCarthy ML, Silberstein CE, Atkins EA, Harryman SE, Sponseller PD, Hadley-Miller NA. Comparing reliability and validity of pediatric instruments for measuring health and well-being of children with spastic cerebral palsy. Dev Med Child Neurol 2002; 44: 468-76.

20 Davis E, Waters E, Mackinnon A, et al. Paediatric quality of life instruments: a review of the impact of the conceptual framework on outcomes. Dev Med Child Neurol 2006; 48: 311-18.

21 Marks D. Models of disability. Disabil Rehabil 1997; 19: 85-91.

22 Oliver M. The politics of disablement. London: Macmillan, 1990.
23 Colver A. Study protocol: SPARCLE-a multi-centre European study of the relationship of environment to participation and quality of life of children with cerebral palsy. BMC Public Health 2006; 6: 105.

24 Dickinson H, Parkinson K, McManus V, et al. Assessment of data quality in a multi-centre cross-sectional study of participation and quality of life of children with cerebral palsy. BMC Public Health 2006 6: 273 .

25 Cummins RA. Comprehensive quality of life scale-intellectual disability, 4th edn. Melbourne: Psychology Research Centre, 1993.

26 Ravens-Sieberer U, Gosch A, Rajmil L, et al. KIDSCREEN-52 quality-of-life measure for children and adolescents. Expert Rev Pharmacoeconomics Outcomes Res 2005; 5: 353-64.

27 Detmar SB, Bruil J, Ravens-Sieberer U, Gosch A, Bisegger C. The use of focus groups in the development of the KIDSCREEN HRQL questionnaire. Qual Life Res 2006; 15: 1345-53.

28 Bisegger C, Cloetta B, von Rueden U, Abel T, Ravens-Sieberer U. Health-related quality of life: gender differences in childhood and adolescence. Soz Praventivmed 2005; 50: 281-91.

29 KIDSCREEN Group Europe. The KIDSCREEN questionnaires. Quality of life questionnaires for children and adolescents—handbook. Lengerich: Papst Science Publisher, 2006.

30 Beaton DE, Bombardier C, Guillemin F, Ferraz MB. Guidelines for the process of cross-cultural adaptation of self-report measures. Spine 2000; 25: 3186-91.

31 Cronbach L. Coefficient alpha and the internal structure of test. Psychometrics 1951; 16: 297-343.

32 Landgraf J, Abetz L, Ware JE. Child Health Questionnaire (CHQ): a user's manual, 2nd edn. Boston, MA: HealthAct, 1999.

33 Palisano R, Rosenbaum P, Walter S, Russell D, Wood E, Galuppi B. Development and reliability of a system to classify gross motor function in children with cerebral palsy. Dev Med Child Neurol 1997; 39: 214-23.

34 Beckung E, Hagberg G. Neuroimpairments, activity limitations, and participation restrictions in children with cerebral palsy. Dev Med Child Neurol 2002; 44: 309-16.

35 Dales LG, Ury HK: An improper use of statistical significance testing in studying covariables. Int J Epidemiol 1978; 7: 373-375

36 Royall R. Model robust confidence intervals using maximum likelihood estimators. Int Stat Rev 1986; 54: 221-26.

37 White-Koning M, Arnaud C, Bourdet-Loubere S, Bazex H, Colver A, Grandjean H. Subjective quality of life in children with intellectual impairment-how can it be assessed? Dev Med Child Neurol 2005; 47: 281-85.

38 Jemta L, Dahl M, Fugl-Meyer KS, Stensman R. Well-being among children and adolescents with mobility impairment in relation to demographic data and disability characteristics. Acta Paediatr 2005 94: 616-23.

39 Brunner HI, Klein-Gitelman MS, Miller MJ, et al. Health of children with chronic arthritis: relationship of different measures and the quality of parent proxy reporting. Arthritis Rheum 2004; 51: 763-73.

40 Appleton PL, Minchom PE, Ellis NC, Elliott CE, Boll V, Jones P. The self-concept of young people with spina bifida: a population-based study. Dev Med Child Neurol 1994; 36: 198-215.

41 King GA, Shultz IZ, Steel K, Gilpin M, Cathers T. Self-evaluation and self-concept of adolescents with physical disabilities. Am J Occup Ther 1993; 47: $132-40$

42 Sallfors C, Hallberg LR, Fasth A. Well-being in children with juvenile chronic arthritis. Clin Exp Rheumatol 2004; 22: 125-30.

43 Sawyer MG, Whitham JN, Roberton DM, Taplin JE, Varni JW, Baghurst PA. The relationship between health-related quality of life, pain and coping strategies in juvenile idiopathic arthritis. Rheumatology 2004; 43: 325-30.

44 Bakoula C, Kapi A, Veltsista A, Kavadias G, Kolaitis G. Prevalence of recurrent complaints of pain among Greek schoolchildren and associated factors: a population-based study. Acta Paediatr 2006; 95: 947-51.

45 Petersen S, Brulin C, Bergstrom E. Recurrent pain symptoms in young schoolchildren are often multiple. Pain 2006; 121: 145-50.

46 Kristjansdottir G. Prevalence of pain combinations and overall pain: a study of headache, stomach pain and back pain among school-children. Scand J Soc Med 1997; 25: 58-63.

47 Albrecht GL, Devlieger PJ. The disability paradox: high quality of life against all odds. Soc Sci Med 1999; 48: 977-88. 